\title{
Canopy Morphology of Pecan Cultivars
}

\section{Bruce W. Wood \\ U.S. Department of Agriculture, Agricultural Research Service, Southeastern Fruit and Tree Nut Research Laboratory, Byron, GA 31008}

Additional index words. Carya illinoinensis, shape, size, form, branch angles, trunks, light interception

\begin{abstract}
Canopy morphology of 83 pecan [Carya illinoinensis (Wangenh.) K. Koch] cultivars differed in structural, size, and form characteristics. Cluster analysis identified two to five distinct classes for canopy height and diameter and their ratio, inclination angles for both major limbs and young shoots with lower-order structures, branch types, and canopy form and volume. Cultivar-related variability in these traits may have the potential for the improvement of pecan cultivars for factors such as light interception, cooling, air movement, and fruiting; thus, there is potential for identifying the development of canopy characteristics adapted to specific site conditions or cultural/management strategies.
\end{abstract}

Orchard crops, especially those grown in a matrix consisting of discrete nonintersecting canopies, such as pecan, typically intercept a maximum of $65 \%$ to $70 \%$ of the available sunlight, with interception usually being far less for much of the life of the orchard (Jackson, 1980). Because production is nearly directly proportional to light interception, if other factors are constant (Loomis and Gerakis, 1975), the effectiveness with which a tree gathers light affects the nature and profitability of a pecan orchard. This effectiveness is largely regulated by the morphological characteristics of the canopy. In the case of tree-nut crops, especially pecan, little is known about the cultivar differences in canopy characteristics.

The pecan tree canopy is a complex solarcollection system possessing leaf and shoot subsystems consisting of myriadial parts (Wilson, 1984). These subsystems are arranged so that they display the photosynthetic apparatus effectively; also, they are derived from an annually repeating nonrandom pattern where the lateral branches of each shoot increment, displayed in a spiraled 2/5 phyllotaxis (Cook, 1979), decreases in length toward the base of the shoot, thus producing a distinct shoot and leaf mosaic. The reiteration and accumulation of these patterns over many years, simplified by the death of some older branches and the accentuation by thickening of others, results in a distinct canopy morphology that changes with ontogeny (Brown, 1974).

Field observations indicate substantial morphological diversity among pecan genotypes; however, this diversity has not been studied nor the degree of genetic control determined. Since structural, shape, and size traits

Received for publication 10 July 1995 . Accepted for publication 20 Oct. 1995. Appreciation is expressed to William Reid, Ray Worley, Tom Crocker, and Fountain Young for providing germplasm for establishment of this study. The cost of publishing this paper was defrayed in part by the payment of page charges. Under postal regulations, this paper therefore must be hereby marked advertisement solely to indicate this fact. can influence cultural and management stratpruning/hedging, pest management), there is need for greater insight into the morphology of pecan tree canopies. This study quantifies several such traits in 83 pecan cultivars.

\section{Materials and Methods}

Eighty-three pecan cultivars were assessed for morphological diversity regarding crown characteristics. Trees were in a commerciallike cultivar planting established by barkgrafting scions to 4-year-old ('Curtis' seedlings) rootstocks on a 9.14-m square spacing on a Norfolk loamy fine sand in 1984. Trees were managed according to Georgia Cooperative Extension Service recommendations for fertilization and pest control and were dripirrigated (Crocker, 1986). Trees were trained to a central leader during the first three growing seasons to facilitate commercial management practices. The planting was thinned on the diagonal in Mar. 1994 when the canopies of the largest trees were about to intersect (10 years old)

The design was a randomized incomplete block (maximum of four single tree blocks) with the independent variable being 83 scion cultivars. Essentially all commercially significant cultivars and many less common cultivars were represented. Dependent variables were measured in Mar. 1995 and consisted of canopy height, canopy width at the widest point, trunk diameter, general canopy shape (form), number of primary stems at midcanopy, inclinaof the canopy, and inclination angle of lateral shoots at midcanopy. Canopy volume, eccentricity (crown height/crown width), and limb form were calculated from these measurements (based on the ratio of the length of the apical shoot produced each growth year to that of the next longest lateral shoot). Data were analyzed using SAS GLM (SAS Institute, 1988) and by Scott-Knott cluster analysis (Gates and Bilbro, 1978; Scott and Knott, egies (such as tree spacing, orchard thinning, tion angle of scaffold limbs on the lowest $25 \%$
1974; Willavize et al., 1980 ) to assess classes within each dependent morphological variable, hence providing distinct groups of nonoverlapping means.

\section{Results and Discussion}

Pecan cultivars differed in all measured morphological traits, with analysis of variance techniques identifying cultivar-related differences and Scott-Knott cluster analysis revealing from two to five distinct classes per trait (Table 1). These data show substantial cultivar-related morphological diversity for several structural, form, and size traits of pecan canopies. While these traits vary with ontogeny and environment (Brown, 1971; Wilson, 1984 ), they approximate those of young bearing trees in commercial plantings just beginning the phase of high nut production.

\section{Structural characteristics}

Major stems. Among the many structural factors influencing tree performance is the number of major stems (meaning the major second-order branches, unless there is only one per tree, where it then would be firstorder) comprising the canopy and the crotch angles exhibited by the associated major scaffold limbs (either second- or third-order). Cluster analysis disclosed at least four distinct classes of stems per tree within the cultivar population (Table 1). Some cultivars had as few as one main stem (i.e., first-order stem), whereas others averaged up to 6.5 per tree. Since the number of main stems influences light interception, canopy shape, structural integrity, and cropping efficiency, this nearly 7-fold range shows substantial intercultivar diversity and potential for developing cultivars with a specific number of stems (types). Correlation analysis indicated a weak negative relationship between the number of stems per tree and the ratio of apical shoot length to that of the longest lateral shoot (i.e., SR; Table 2).

Cultivars with few major stems (e.g., 'GraTex', 'Forkert', 'Moreland', 'Maramec', 'Russell', 'Shoshoni', and 'Colby') generally displayed foliage on scaffold limbs that was quasispiral around the main stems, thus minimizing limb superposition and maximizing exposure to sunlight and air circulation. This characteristic is favorably influenced by the $2 / 5$ phyllotaxis, or quincunial series, which confers a near ideal angle - from the perspective of minimizing shading-for leaf and branch distribution (Cook, 1979; Huntley, 1970). In contrast, cultivars with multiple stems (e.g., 'Stuart', 'Tejas', 'Jackson, and 'Schley') exhibited an increased level of overlapping by scaffold limbs, thus increasing superposition. However, such cultivars exhibited a phototropic bending of limbs toward well-lighted regions, resulting in a tendency to reestablish the geometrical symmetry originally conferred by the quincunial series innate to pecan. Such cultivars would, therefore, appear to be at a disadvantage for efficiently intercepting light and for maximizing air movement, which is 
Breeding, Cultivars, Rootstocks, \& Germplasm Resources

Table 1. Canopy characteristics of pecan cultivars. Classification is based on Scott-Knott cluster analysis of 10-year-old trees. ${ }^{2}$

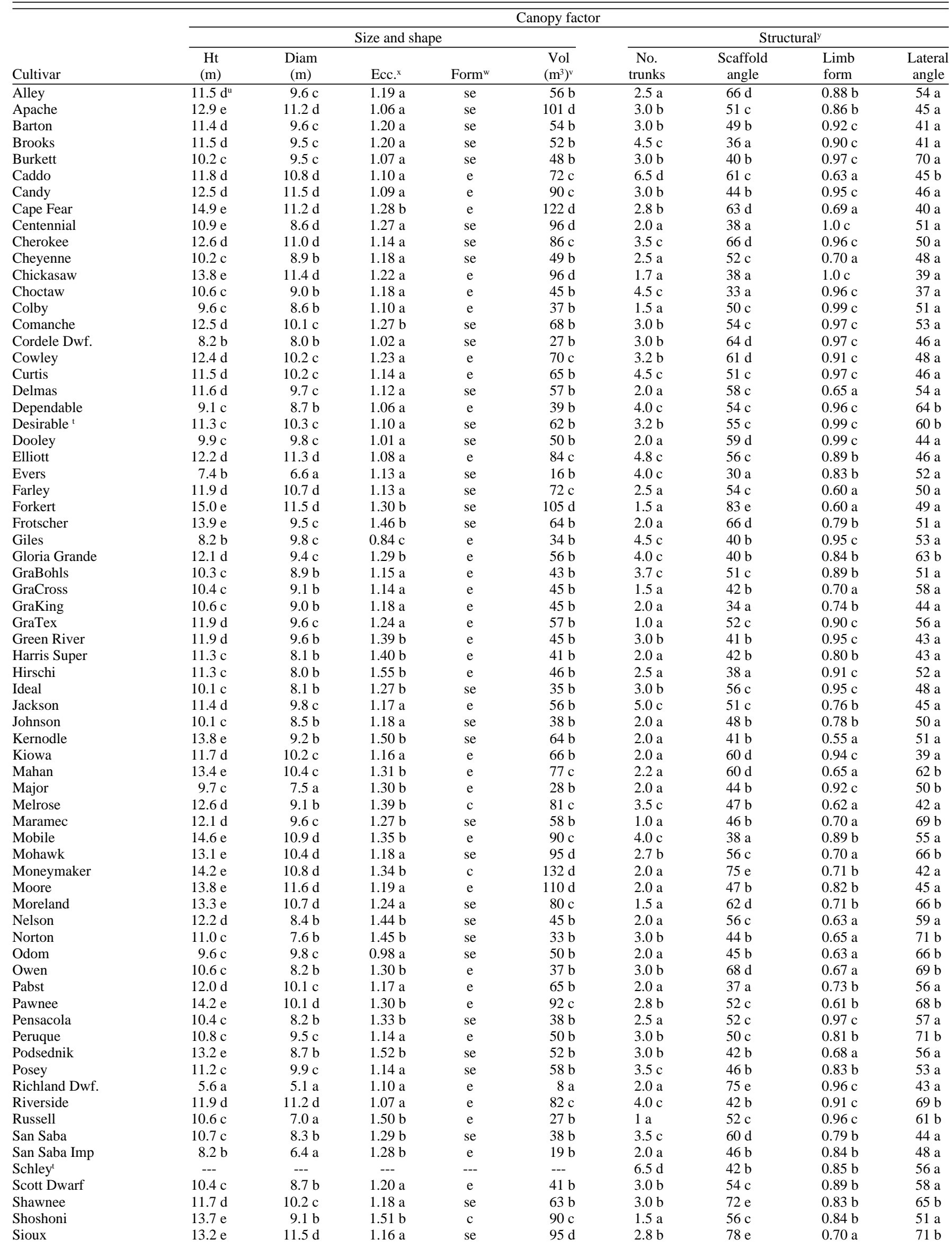




\begin{tabular}{|c|c|c|c|c|c|c|c|c|c|}
\hline \multirow[b]{3}{*}{ Cultivar } & \multicolumn{9}{|c|}{ Canopy factor } \\
\hline & \multicolumn{5}{|c|}{ Size and shape } & \multicolumn{4}{|c|}{ Structuraly $^{\mathrm{y}}$} \\
\hline & $\begin{array}{l}\mathrm{Ht} \\
(\mathrm{m})\end{array}$ & $\begin{array}{l}\text { Diam } \\
(\mathrm{m})\end{array}$ & Ecc. $^{x}$ & Form $^{\mathrm{w}}$ & $\begin{array}{c}\text { Vol } \\
\left(\mathrm{m}^{3}\right)^{\mathrm{v}}\end{array}$ & $\begin{array}{l}\text { No. } \\
\text { trunks }\end{array}$ & $\begin{array}{c}\text { Scaffold } \\
\text { angle }\end{array}$ & $\begin{array}{l}\text { Limb } \\
\text { form }\end{array}$ & $\begin{array}{c}\text { Lateral } \\
\text { angle }\end{array}$ \\
\hline Squirrels Del. & $11.2 \mathrm{c}$ & $8.8 \mathrm{~b}$ & $1.28 \mathrm{~b}$ & se & $45 \mathrm{~b}$ & $3.0 \mathrm{~b}$ & $64 \mathrm{~d}$ & $0.71 \mathrm{~b}$ & $55 \mathrm{a}$ \\
\hline Starkings & $12.1 \mathrm{~d}$ & $8.3 \mathrm{~b}$ & $1.47 \mathrm{~b}$ & $\mathrm{c}$ & $66 \mathrm{~b}$ & $3.5 \mathrm{c}$ & $75 \mathrm{~d}$ & $0.79 \mathrm{~b}$ & $45 \mathrm{a}$ \\
\hline Stuart & $13.8 \mathrm{e}$ & $9.8 \mathrm{c}$ & $1.46 \mathrm{~b}$ & $\mathrm{e}$ & $72 \mathrm{c}$ & $6.0 \mathrm{~d}$ & $43 \mathrm{~b}$ & $0.98 \mathrm{c}$ & $42 \mathrm{a}$ \\
\hline Success & $11.3 \mathrm{c}$ & $10.2 \mathrm{c}$ & $1.12 \mathrm{a}$ & $\mathrm{e}$ & $63 \mathrm{~b}$ & $2.5 \mathrm{~b}$ & $55 \mathrm{c}$ & $0.97 \mathrm{c}$ & $67 b$ \\
\hline Sumner & $12.5 \mathrm{~d}$ & $10.3 \mathrm{c}$ & $1.23 \mathrm{a}$ & se & $69 c$ & $4.2 \mathrm{c}$ & $70 \mathrm{e}$ & $0.71 \mathrm{~b}$ & $67 \mathrm{~b}$ \\
\hline Teche & $10.6 \mathrm{c}$ & $8.1 \mathrm{~b}$ & $1.31 \mathrm{~b}$ & se & $26 \mathrm{~b}$ & $3.0 \mathrm{~b}$ & $32 \mathrm{a}$ & $0.99 \mathrm{c}$ & $45 \mathrm{a}$ \\
\hline Tejas & $11.7 \mathrm{~d}$ & $9.5 \mathrm{c}$ & $1.22 \mathrm{a}$ & $\mathrm{e}$ & $53 \mathrm{~b}$ & $6.0 \mathrm{~d}$ & $43 \mathrm{~b}$ & $0.70 \mathrm{a}$ & $56 \mathrm{a}$ \\
\hline Van Deman & $13.1 \mathrm{e}$ & $10.2 \mathrm{c}$ & $1.28 \mathrm{~b}$ & $\mathrm{e}$ & $72 \mathrm{c}$ & $4.0 \mathrm{c}$ & $54 \mathrm{c}$ & $0.68 \mathrm{a}$ & $65 \mathrm{~b}$ \\
\hline Waukeenah & $13.8 \mathrm{e}$ & $9.1 \mathrm{~b}$ & $1.53 \mathrm{~b}$ & se & $60 \mathrm{~b}$ & $3.0 \mathrm{~b}$ & $42 \mathrm{~b}$ & $0.92 \mathrm{c}$ & $57 \mathrm{a}$ \\
\hline Western Sch. & $11.9 \mathrm{~d}$ & $10.3 \mathrm{c}$ & $1.18 \mathrm{a}$ & $\mathrm{se}$ & $66 \mathrm{~b}$ & $3.0 \mathrm{~b}$ & $49 c$ & $0.76 \mathrm{~b}$ & $61 b$ \\
\hline Wichita & $10.4 \mathrm{c}$ & $9.3 \mathrm{~b}$ & $1.12 \mathrm{~s}$ & $\mathrm{se}$ & $52 \mathrm{~b}$ & $3.0 \mathrm{~b}$ & $53 \mathrm{c}$ & $0.88 \mathrm{~b}$ & $71 \mathrm{~b}$ \\
\hline Woodard & $12.4 \mathrm{~d}$ & $8.4 \mathrm{~b}$ & $1.48 \mathrm{~b}$ & $\mathrm{se}$ & $48 \mathrm{~b}$ & $2.0 \mathrm{a}$ & $50 \mathrm{c}$ & $0.94 \mathrm{c}$ & $46 \mathrm{a}$ \\
\hline Woodroof & $12.8 \mathrm{~d}$ & $8.4 \mathrm{~b}$ & $1.53 \mathrm{~b}$ & se & $47 \mathrm{~b}$ & $1.5 \mathrm{a}$ & $75 \mathrm{e}$ & $0.96 \mathrm{c}$ & $43 \mathrm{a}$ \\
\hline
\end{tabular}

${ }^{2}$ Date are from 10-year-old trees planted on a 9.14-m square spacing with diagonal trees thinned at age 10.

y Number of main stems per tree, inclination angle of lower scaffold limbs (degrees), limb form as defined by the length of the apical shoot divided by the length of the longest lateral shoot from current-season growth, and inclination angle of lateral shoot (degree).

${ }^{x}$ Eccentricity (Ecc.) or ratio of crown height divided by crown width.

${ }^{\mathrm{w}}$ Canopy shape approximated one of several geometric forms: $\mathrm{e}=$ full ellipse or prolate spheroid, $\mathrm{c}=\mathrm{cylindrical}$, and se $=$ semi-ellipse or half a prolate spheroid. virtual volume of tree canopy.

uDifferent letters within each column, or dependent variables, represent different classes as identified by Scott-Knott cluster analysis. Means associated with different letters within each column are therefore statistically different according to Scott-Knott cluster analysis with $\alpha \leq 0.10$.

'Data from trees of similar age but from an adjacent orchard treated in an identical manner.

Table 2. Pearson correlation coefficients $(r)$ for morphological traits of pecan canopies.

\begin{tabular}{llllccccc}
\hline & Diam $^{\mathrm{z}}$ & Ecc. $^{\mathrm{y}}$ & Vol $^{\mathrm{x}}$ & Stems $^{\mathrm{w}}$ & IALS $^{\mathrm{v}}$ & SR $^{\mathrm{u}}$ & IAS $^{\mathrm{t}}$ & Diam $^{\mathrm{s}}$ \\
\hline Height $^{\mathrm{r}}$ & $0.63^{* * *}$ & $0.34^{* *}$ & $0.76^{* *}$ & 0.01 & $0.16^{*}$ & 0.06 & 0.02 & $0.59^{* *}$ \\
Diameter & 0 & $-0.51^{* *}$ & $0.91^{* *}$ & $0.19^{*}$ & $0.16^{*}$ & 0.09 & 0.05 & $0.73^{* *}$ \\
Ecc. & 0 & 0 & $-0.24^{* *}$ & $-0.21^{*}$ & -0.03 & 0.13 & 0.06 & $-0.25^{*}$ \\
Volume & 0 & 0 & 0 & 0.09 & $0.24^{*}$ & 0.01 & 0.09 & $0.71^{* *}$ \\
Stems & 0 & 0 & 0 & 0 & -0.12 & $-0.51^{* *}$ & -0.07 & 0.04 \\
IALS & 0 & 0 & 0 & 0 & 0 & $-0.49^{* *}$ & 0.06 & 0.16 \\
SR & 0 & 0 & 0 & 0 & 0 & 0 & $-0.30^{* *}$ & 0.11 \\
IAS & 0 & 0 & 0 & 0 & 0 & 0 & 0 & 0.13 \\
\hline
\end{tabular}

${ }^{\mathrm{z}}$ Diameter of tree crown at widest point.

${ }^{y}$ Eccentricity (Ecc.) or ratio of crown height divided by crown width.

xVirtual volume of tree canopy.

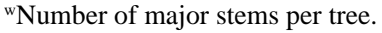

'Inclination angle of scaffold limbs (IALS).

"Ratio of length of apical shoot to that of the longest lateral shoot (SR).

tInclination angle of lateral shoots (IAS).

s Diameter of tree trunk.

${ }^{\mathrm{r}}$ Height of canopy, excluding trunk height.

${ }^{*}, * *$ Pearson correlation coefficients: $\alpha \leq 0.05$ or 0.001 , respectively; those without asterisks are nonsignificant at $\alpha \leq 0.10$.

important for minimizing diseases, as compared to cultivars with few stems. The potentially adverse influence of this characteristic on important physiological processes, such as photosynthesis, respiration, and transpiration (Kramer and Kozlowski, 1979), would tend to indicate that the multiple-stem trait is a major disadvantage when cultivating pecan at locations with significant cloud cover or high temperatures. It is, therefore, paradoxical that multistem cultivars (e.g., 'Stuart' and 'Schley') are most common in the southeastern United States, where the percentage of available sunlight is low and the air temperature is high during the growing season. Multiple-stem trees also would tend to be more susceptible to wind-induced limb breakage and subsequent economic losses than those with only one or two major stems.

Inclination angles of major scaffold limbs. The inclination angle of major scaffold limbs with their mother stems also differed among the cultivars (Table 1). Most cultivars exhib- ited rather narrow limb angles, ranging from $40^{\circ}$ to $57^{\circ}$; however, a few $(9 \%)$ exhibited angles $>70^{\circ}$. This angle of inclination can influence the display of foliage to the sun and also the deposition of water. For example, narrow angles let water collect near the trunk, whereas horizontal branches cause more water to drip toward the outside of the crown (Busgen and Munch, 1929). While there are exceptions to the rule, limb strength tends to increase as the degree of acuteness diminishes (Brown, 1974). These wide-angled types would not only tend to possess stronger limbs, but also tend to produce canopies with greatest crown width at the base of the crown (semiellipse), thus enhancing sunlight interception (Ferree, 1994). While it is common for limb angles to change with tree age and position, certain cultivars exhibited desirable wide angles; these would be useful parents. However, the number of stems per tree was not strongly associated with other measured traits $(r \leq 0.50$; Table 2).
Limb form. Three classes were noted for limb form-defined as the ratio of the length of the apical shoot to that of the next longest lateral shoot from the same year's growth: 1) the primary lateral shoot was about the same length as the apical shoot; 2 ) it was $\approx 70 \%$ to $80 \%$ as long; and 3) it was $\approx 50 \%$ to $60 \%$ as long (Table 1). Cultivars within these classes generally exhibited distinct limb patterns. For example, the $12 \%$ of the population possessing apical shoots about twice the length of their longest lateral shoot exhibited branches that tended to be straight and displayed an open branch mosaic (aperirecto), thus facilitating the penetration of sunlight into the interior of the canopy. Branches with lateral shoots of about the same length as the apical shoot usually produced forked branches with closed branch mosaics (clistofortificat) and impeded light penetration into the interior of the canopy.

The branch/leaf mosaics produced by the two extreme classes, aperirecto vs. clistofortificat, conferred distinctly different canopy morphologies. For example, the aperirecto form exhibited a multilayer characteristic that would be expected to facilitate light penetration to the interior of the canopy. Superior intracanopy light penetration might therefore be expected in 'Caddo', 'Cape Fear', 'Cheyenne', 'Curtis', 'Delmas', 'Farley', 'Forkert', 'GraCross', 'Kernodle', 'Mahan', 'Melrose', 'Maramec', 'Mohawk', 'Nelson', 'Norton', 'Odom', 'Owen', 'Sioux', 'Tejas', 'Van Deman', and 'Western Schley', especially in those with relatively wide lateral shoot angles (see discussion below on inclination of lateral angles). This increased light indicates that aperirecto forms, especially those with wide lateral shoot angles, likely would exhibit less branch death in the interior of the canopy, better interior fruiting, and a larger volume of the canopy setting fruit. Clistofortificatcanopies, especially those with relatively narrow inclination angles, tended to 
display foliage in a quasi-monolayer; thus, intracanopy light penetration was retarded.

Additionally, tree form has ramifications regarding cultural practices and pest management strategies. For example, the reduced light penetrability of clistofortificat trees indicates a likely disadvantage in cultural practices where mechanical hedging or wisping are used because of the need for excellent light penetration into the canopy. Similarly, the innate openness of aperirecto types would be expected to allow for better penetration of pesticides delivered via ground-based, air-blast sprayers or by aircraft, thus enhancing the effective use of pesticides. Additionally, aperirecto types also may confer greater air movement, thus influencing the level of tree susceptibility in orchards to moisturesensitive disease pests, such as pecan scab [Cladiosporium caryigenum (Ell. \& Langl.) Gottwald] (Gottwald, 1985).

Inclination angles of lateral shoots. Cultivars also had diverse lateral shoot angles (i.e., the angle of the crotch formed by lateral shoots). There were narrow (angustiangulus), wide (latiangulus), and clinal intermediate angle types (Table 1). These types carry major horticultural ramifications, depending on form type and shoot angle, because of their potential influence on light penetration into the canopy. The branch mosaic of these trees appeared to be increasingly open as the acuteness of inclination decreased, thus indicating greater light penetration and air movement. There was a slight inverse association $(r=0.30$; Table 2$)$ between this angle of inclination and that of the lateral shoot type (SR), with aperirecto forms tending to have wider shoot angles, but no association with any other morphological trait (Table 2). The aperirecto type that also exhibited the latiangulus trait was limited to nine cultivars: 'Mahan', 'Maramec', 'Mohawk', 'Norton', 'Odom', 'Owen', 'Pawnee', 'Sioux', and 'Van Deman' (Table 1). Additionally, 'Sumner' is a commercially important cultivar that has a borderline tendency for this trait combination. Clistofortificat forms with the likely desirable latiangulus trait were 'Burkett', 'Dependable', 'Desirable', 'Riverside', 'Russell', and 'Success' (Table 1). The commercially important cultivar Wichita was borderline and would, therefore, have a tendency to exhibit these characteristics.

\section{Canopy form}

General canopy form of all cultivars fell within one of three shapes: full ellipse (48\%), semi-ellipse (48\%), or cylindrical (4\%) (Table $1)$. Since differing forms confer differing virtual canopy volumes, there were marked differences among cultivars, with some occupying several times the volume as others. Cultivars exhibiting the most pronounced aperirecto forms (limb ratio $<0.65$ ) possessed canopies that were best described by a semi-ellipse (i.e., greatest width at the base of the crown). Conversely, at 10 years old, the most distinct clistoforticate forms (ratios $>0.95$ ) produced canopies with a roughly equal number of cul- tivars classified as either semi- or full ellipses (maximum diameter at midcrown), but almost all of the semi-elliptical forms that were distinctly clistoforticate $(>0.95)$ also possessed wide crotch angles for scaffold limbs.

These data are interpreted to indicate that as trees age, aperirecto forms are more likely to possess canopies that are widest at the bottom of the crown, whereas clistoforticat forms tend to have maximum widths at midcanopy (or higher). This conclusion is validated by the general appearance of aged trees of the clistoforticat type and seems to be due to a combination of at least two factors: 1 ) the tendency for lower branches to be farther extended from the tree trunk by aperirectos types, and 2) a greater tendency for the lower limb of the clistoforticat types to be shaded out and eventually die due to reduced light penetration to the lower canopy. The canopies of clistoforticat types, especially those with relatively narrow crotch angles for lateral shoots, would therefore be more likely to exhibit shade-induced crown form changes, becoming vase-like in form with increasingly flattened crown tops as the tree ages. Examples of this are old 'Schley' and 'Stuart' trees in crowded orchards in which nut production and quality has declined. Since exposure of the maximum amount of the canopy surface to sunlight generally occurs when trees are semi-ellipses (widest at the bottom) (Ferree, 1994), cultivars with a semi-elliptical form would be expected to have an advantage over full elliptical forms.

\section{Canopy size}

Canopy height differed among cultivars by 3 -fold, ranging from $5.6 \mathrm{~m}$ for the 'Richland Dwarf' to $15 \mathrm{~m}$ for 'Forkert', whereas crown width differed 2.4-fold, from $5.2 \mathrm{~m}$ for 'Richland Dwarf' to 12.2 m for 'Cape Fear' (Table 1). There were five distinct crown height and four crown width categories. Eccentricity, or the ratio of crown height to diameter, differed such that three distinct classes were identified. All but two cultivars ('Giles' and 'Odom') had crown heights that exceeded the crown diameter. About $17 \%$ of the tested cultivars possessed crowns about twice as tall as wide, while another $80 \%$ possessed canopies slightly taller than wide. There were only slight interrelationships $(r \leq 0.76)$ among these three traits and that of trunk diameter (Table 2). Canopy height is especially important in that it greatly influences the density and geometry of orchards. Since it is a general rule with most orchard crops that tree height should not exceed twice the distance of the open space between trees (Ferree, 1994), the 2-fold difference in canopy height exhibited by some cultivars in this study indicates that optimum intertree spacing will depend greatly on cultivar. This consideration would be expected to be especially important for pecan since it is a rather shade-intolerant crop (Fowells, 1965); however, orchard spacing recommendations rarely take into account cultivar size differences (personal observation).

The data presented characterize the mor- phological diversity of canopy traits of 83 pecan cultivars and present, for the first time, basic information relating to the suitability of cultivars to certain orchard situations. The identification of two to five classes per trait, plus that of clinal variability, is taken as evidence that these particular traits most likely are quantitatively inherited and that there is potential to breed cultivars with desirable canopy morphology. Variability in limb form, inclination angles of main stems and of lateral shoots, branch forms, canopy shapes, and canopy size carry substantial ramifications (i.e., light interception, air movement, structural strength, space use, foliar cooling, fruiting, and pest control) regarding cultural and management strategies, and merit consideration when selecting cultivars for establishing orchards or using as parents in breeding. The low correlation coefficients among these traits indicate a lack of strong genetic linkages with each other.

\section{Literature Cited}

Brown, C.L.. 1974. Growth and form, p. 125-165. In: M.H. Zimmermann and C.L. Brown (eds.). Trees: Structure and function. Springer-Verlag, New York.

Busgen, M. and E. Munch. 1929. The structure and life of forest trees. 3rd ed., translation by $\mathrm{T}$. Thomson. Wiley, New York.

Cook, T.A. 1979. The curves of life. Dover Publications, New York.

Crocker, T.F. 1986. Commercial pecan production in Georgia. Univ. of Georgia Coop. Ext. Serv. Bul. 609.

Ferree, D.C. 1994. Orchard management systems, p. 131-142. In: C.J. Arntzen and E.M. Ritter (eds.). Encyclopedia of agricultural science (vol. 3). Academic, San Diego.

Fowells, H.A. 1965. Pecan, p. 121-123. In: H.A. Fowells (ed.). Silvics of forest trees of the United States. U.S. Dept. Agr., Agr. Hdbk. 271.

Gates, C.E. and J.D. Bilbro. 1978. Illustration of a cluster analysis method for measure separation. Agron. J. 70:462-465.

Gottwald, T.R. 1985. Influence of temperature, leaf wetness period, leaf age, and spore concentration on infection of pecan leaves by conidia of Cladosporium caryigenum. Phytopathology 75:190-194.

Huntley, H.E. 1970. The divine proportion: A study in mathematical beauty. Dover Publications, New York.

Jackson, J.E. 1980. Light interception and utilization by orchard systems, p. 208-267. In: J. Janick (ed). Horticultural Rev. (vol. 2). AVI, Westport, Conn.

Kramer, P.J. and T.T. Kozlowski. 1979. Physiology of woody plants. Academic, New York.

Loomis, R.S. and P.A Gerakis. 1975. Productivity of agricultural ecosystems, p. 145-172. In: J.P. Cooper (ed.). Photosynthesis and productivity in different environments. Cambridge Univ. Press, London.

SAS Institute. 1988. SAS/STAT user's guide, release 6.03 ed. SAS Inst., Cary, N.C.

Scott, A.J. and M. Knott. 1974. A cluster analysis method of grouping means in the analysis of variance. Biometrics 30:507-512.

Willavize, S.A., S.G. Carmer, and W.M. Walker. 1980. Evaluation of cluster analysis for comparing treatment means. Agron. J. 72:317-320.

Wilson, B.F. 1984. The growing tree. Univ. of Massachusetts Press, Amherst. 